\title{
Faultless Disagreement, Assertions and the Affective-Expressive Dimension of Judgments of Taste
}

\author{
Filip Buekens
}

Received: 9 January 2011 / Accepted: 25 April 2011/

Published online: 31 May 2011

(C) The Author(s) 2011. This article is published with open access at Springerlink.com

\begin{abstract}
Contextualists and assessment relativists neglect the expressive dimension of assertoric discourse that seems to give rise to faultless disagreement. Discourse that generates the intuition makes public an attitudinal conflict, and the affectiveexpressive dimension of the contributing utterances accounts for it. The FDphenomenon is an effect of a public dispute generated by a sequence of expressing opposite attitudes towards a salient object or state of affairs, where the protagonists are making an attempt to persuade the other side into joining the other's camp.
\end{abstract}

Keywords Faultless disagreement · Expressivism · Assertion-pluralism · Max Kölbel · John Macfarlane · Mitchell Green

\section{Introduction}

What is the function of expressing an attitude towards an object compared with asserting or conversationally implicating that one has that attitude ${ }^{1}$ I explore this question in a discussion of the alleged phenomenon of 'faultless disagreement' (FD) that seems characterize so-called 'subjective discourse'. I argue that there is no such thing as faultless disagreement, for there is not one proposition the truth of which two speakers can disagree about and yet both be right. Both the sense of conflict and faultlessness derive from the expressive dimension of the speech acts involved in subjective discourse.

\footnotetext{
${ }^{1}$ Asking for the function of $\mathrm{X}$ is to ask: because of what is $\mathrm{X}$ there? What is the reason $\mathrm{X}$ is there? (Wright 1973).

F. Buekens $(\bowtie)$

Tilburg Institute for Logic and Philosophy of Science, Tilburg University, PB 90153,

5000 LE Tilburg, Netherlands

e-mail: f.a.i.buekens@uvt.nl

F. Buekens

Department of Philosophy, University of Leuven, Leuven, Belgium
} 
The focus is on active disagreement. You and I may be in a state of disagreement over whether Brahms is better than Mahler or whether roller coasters are fun even if we have no knowledge of each other's existence. Only when we actively dispute matters of taste (and thereby both come to know we have such a dispute) will the affective-expressive dimension of utterances play a role in explaining (away) the alleged phenomenon of faultless disagreement. ${ }^{2}$ The FD-phenomenon is an effect of a public dispute generated by a sequence of expressing opposite attitudes towards a salient object or state of affairs, where the protagonists are making an attempt to persuade the other side into joining the other's camp. ${ }^{3}$

Semantic approaches cannot account for the affective-expressive dimension which creates the sense of conflict (section "Faultless Disagreement" and "Problems with Faultless Disagreement"). ${ }^{4}$ In section "The Assertive Dimension" I sketch a version of speech act pluralism that allows utterances to have both an assertive and an expressive dimension (there may be other dimensions as well). Crucial to the approach will be the gap between the semantic content and what we assert using a sentence with compositionally-determined truth conditions. In the final section I offer an account of the function of the affective-expressive dimension of utterances based on insights from Bar-on and Long (2001) and Green (2007, 2008), but going back to an important observation by Immanuel Kant made in his Critique of the Power of Judgment: when expressing an attitude (but not when merely stating or asserting that one has that attitude), one speaks with 'a universal voice, and lays claim to the consent of everyone' (as he put it). I connect that insight with the distinctive role of empathy in a proper understanding the affective-expressive dimension of a speech act involving a judgment of taste. The background theory is a version of semantic minimalism combined with speech act pluralism, here understood as the (uncontroversial) claim that one can perform different speech acts, hence create different pragmatic commitments with one single utterance and not necessarily in the more radical sense, defended by semantic minimalists who contend that the content of 'what the speaker said' is radically underdetermined by the compositionally determined semantic content of the utterance (Cappelen and LePore 2004; Borg 2004). ${ }^{5}$ On my way to that conclusion, I will argue that the individuation of the content of what's asserted by the speakers involved is constrained by whether it fits the norm for assertion, thus giving norms for speech acts not only the role of a constitutive principle for individuating the act (in this case: the act of assertion), but also a role in selecting a suitable content for what the speaker asserted or can be taken to have asserted. What the speaker can be taken to

\footnotetext{
${ }^{2}$ The distinction between disagreement as state and activity is made by Cappelen and Hawthorne (2009) and MacFarlane (2009). Discussions about moral disagreement often blur that distinction. I owe the suggestion to speak of an affective-expressive dimension' to Barry Stroud.

${ }^{3}$ I further explore a line of argument initiated in Buekens (2009).

4 'Expression' and 'expressing' are notoriously vague concepts. I use the term 'expressive dimension of an utterance' more or less in the sense some words too (like derogatory terms, or racist slurs) have, apart from a descriptive content, also an expressive dimension (Potts 2006). Owens (2006) distinguishes expressing a belief and indicating that one has a belief, and stresses the spontaneity in expressing, and the implicaturelike aspect of indicating.

${ }^{5}$ The view explored here bears some resemblance to Boisvert's 'Dual Use Principle, which says that speakers can simultaneously perform expressive and assertive illocutionary acts. I hope to explore and discuss speech act pluralism (in this sense) elsewhere.
} 
have asserted depends on the semantic content of the sentence uttered, but also on background assumptions about the speaker, his intentions, and contextual matters (Soames 2002, 2003, 2007).

I should also stress that the notoriously over-used concept of expression will be given a restricted, slightly technical reading, to be explored below. What I do oppose are purely semantic accounts of the 'subjectivity of a discourse'. That such discourse is 'covertly about a speaker (or perhaps a larger group picked out by the speaker's context and intention)', as John MacFarlane (2007a, p.17) puts it is true but misses the affective-expressive dimension because speaking about one's own sentiments or feelings (i.e. representing oneself as having them) differs from expressing them. Moreover, speaking about the sentiments of a larger group to which the speaker belongs is not subjective discourse at all, does not give rise to the characteristic faultlessness observed in disputes over matters of taste, and doesn't constitute a motivation for the semantic apparatus used to account for the phenomenon. Or so I will argue.

\section{Faultless Disagreement}

Assessment relativists hold that certain uses of predicates of personal taste give rise to faultless disagreement (henceforth: FD): two utterances $u$ and $u$ ' semantically expressing $p$ (i.e. true iff $p$ ) and its negation not- $p$ (i.e. true iff not- $p$ ) can both be truthfully uttered by different speakers, and both are right - they haven't made a cognitive or epistemic mistake and no semantic misunderstanding is involved. Consider two examples drawn from recent contributions to the debate (Lasersohn 2005):

\section{(Roller coaster)}

A: The roller coaster is fun!

B: No, it's not fun.

\section{(Chili tasting)}

A: The chili is tasty.

$\mathrm{B}$ : No, the chili is not tasty!

Proponents of FD maintain that there is a difference between disagreements over objective matters of fact and disagreements over non-objective matters of personal opinion or taste, and that the latter type of disagreement can be faultless. Both examples are meant to illustrate this phenomenon and FD is taken to be evidence for the 'new relativism' (Kölbel 2009, p. 16). ${ }^{6}$ Lasersohn $(2005$, p. 622) adds that 'it is not the case that one of them is right and the other is wrong. They are both is some sense right... How can that be?'

There exists, however, an old argument to the effect that FD is impossible. As Lasersohn (2005, p. 445) points out, many have argued that statements expressing matters of opinion or personal taste don't have truth conditions and do not express propositions. They are non-assertive acts of what Lasersohn calls 'affective expression', and best compared with reactions like 'Yuck!' or 'Cool!' or 'Yummy!'

\footnotetext{
${ }^{6}$ As Lasersohn puts it, '(FD) will allow for the possibility that two utterances express identical semantic content, but with one of them true and the other one false' (Lasersohn 2005, p. 662).
} 
or 'Dunno!' which lack truth-apt content and express a subjective reaction towards a contextually salient object or state of affairs. The assessment relativist replies that, since (i) FD is (according to him) a real phenomenon and (ii) disagreement requires that the speech acts contribute mutually excluding propositional contents (the proposition affirmed by $\mathrm{A}$ is denied in B's contribution), the semanticist is challenged to account for the semantic properties of the sentences expressed, given that, as MacFarlane (2007b, p. 18) puts it, the truth of the claims put forward depends not just on how things are, but also on how things are with some subject (or subjects) who is (are) not an explicit part of the subject-matter of the sentence. Assessment relativists hold that a semantic account of evaluative sentences requires a relativized notion of truth: the semantic value of the proposition expressed by a sentence in a context of utterance $\mathrm{c}_{\mathrm{U}}$ must be relativized to an index or circumstance of evaluation $\mathrm{c}_{\mathrm{E}}$ not only including a possible world but other parameters as well, including a taste parameter or a judge, or perhaps a perspective. Assessmentrelativists hold that it is the standard or perspective determined by the assessor (which can, but need not be the assessor's own standard or perspective) that is relevant. In discourse that generates FD, the assessor selects his own standards as those against which the proposition presented with will be evaluated as true or false.

The official target of the assessment relativist is a contextualist approach to the phenomenon. Contextualists hold that the semantics of predicates of personal taste can be modeled after David Kaplan's approach to indexicals and demonstratives, which assigns them a content relative to a context of utterance (Kaplan 1989), given their character or meaning. The context of utterance provides a semantic value for the indexical parameter in the semantic structure of the relevant adjective, which is then contributed to the proposition expressed. How exactly the context of utterance provides the required content is a matter of dispute. One could, for example, extend John Perry's (1986/1998) proposal and argue that the standard of the speaker is an unarticulated constituent of the proposition expressed by the speaker's utterance and identified by reading off her communicative intentions. Another proposal would be to postulate hidden indexical parameters in the lexical-semantic structure of predicates of personal taste and define their meaning in terms of Kaplanesque character-rules with the standards of the speaker in the context of utterance as their values.

Both families of semantic proposals (contextualism and assessment-relativism) neglect the expressive-affective dimension of contributions to discourse which generates FD. The use of sentences like That's fun or The chili is not tasty at all can generate asserted contents to the effect that the speaker (or someone else) has, or represents herself as having a certain attitude towards the object under discussion (Bar-On and Long 2001), but they can, in tandem with the assertive use, also be used to express those attitudes. ${ }^{7}$ Expressing one's subjective condition via utterances that also enjoy an assertive dimension changes the context of the conversation ways different from, and irreducible to, the way the assertive dimension of that utterance changes the context. Acknowledging the expressive dimension of these utterances

\footnotetext{
7 The real difficulty here is not so much that agents can perform two acts with one token, but that they express attitudes using a language, i.e. a system for which it is essential that utterances in that language serve $a$ plurality of ulterior purposes. Primitive expressive signals (frowns, smiles, 'Yuck!') lack that distinctive feature.
} 
involves the following distinctions: a speaker (i) utters a sentence that is true iff $p$, (ii) thereby asserts that $p^{*}$ (where $p^{*}$ is often an expanded or modified version of the semantic content of the sentence he utters), and (iii) moreover expresses an attitude (emotion, feeling) by uttering the sentence with its designated semantic content.

The expressive-affective dimension of an utterance will be explored in the course of this paper, but one thing should be clear from the outset: the Frege-Geach-Searle objections to classic expressivist or emotivist accounts of moral and aesthetic discourse are well taken. ${ }^{8}$ The fact that an utterance may carry an affectiveexpressive dimension does not preclude that the sentence used on that occasion has the same semantic content as when it occurs in conversations where its use doesn't carry that dimension or cases where the asserted content is unaccompanied by an affective-expressive dimension. ${ }^{9}$ I may very well use the sentence The roller coaster is fun to assert that a lot of people think that the roller coaster is fun, as when I am summarizing an extensive empirical survey about favorite theme park attractions. Any problem with disagreeing with those asserted contents has less to do with the use of predicates of personal taste rather than, for example, well known problems about the truth conditions of generics, and disagreement about the truth value of generic statements is not even prima facie faultless. These uses do not support the Stevensionan or Ayerian emotivist proposal that sentences used for those purposes lack compositionally determined truth conditions or (equivalently) do not express truth-evaluable propositions. They are compositionally integrated in the language speakers use to realize their communicative purposes.

An important feature of accounts of the FD phenomenon by its proponents is the unisono rejection of the classical Ayer-type expressivism, an account on which it is impossible to dispute questions of value because is impossible to dispute questions about value' (Ayer 1948, p. 110, quoted by Kölbel 2003, p.65). Kölbel's dialectical move is to argue from the existence of an FD intuition to a rejection of classical expressivism: since, according to Kölbel, FD is a genuine phenomenon involving incompatible propositions, expressivism must be rejected (cf. supra). Cappelen and Hawthorne (2009) reject classic expressivist accounts and opt for 'playing the game of broadly truth-conditional semantics' (p. 112-113, ms). ${ }^{10}$ Neither Kölbel, MacFarlane or Wright consider whether semantically kosher alternatives to traditional expressivism can account for the undisputed phenomenon that uttering sentences like This is tasty in the right tone of voice and in conversations in which they characteristically generate the FD intuition express subjective states, and when denied by others, reveal an attitudinal conflict about a subject matter. ${ }^{11}$ In sum: a speech act may carry different audiencedirected dimensions: an assertive dimension (governed by norms of assertion) and an affective-expressive dimension governed, as we will see, by a Kantian commitment to universality, and with the distinctive aim of social persuasion.

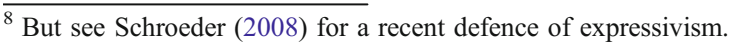

9 'A thought may have just the same content whether you assent to its truth or not; a proposition may occur in discourse now asserted, now unasserted, and yet be recognizably the same proposition' (Geach 1965, p. 449).

${ }^{10}$ See also Soames $(2002,2007)$ for further elaboration of the distinction between semantic content and the content asserted. Accepting this terminology doesn't entail that contextualist insights and intuitions should be overlooked.

11 There are of course other sources of non-coassertability. Consider: "P, but I don't believe that P".
} 


\section{Problems with Faultless Disagreement}

All parties acknowledge that when A utters Roller coasters are fun in Roller coaster he speaks on the basis of his own affective reaction to roller coasters and is authoritative about it (Lasersohn 2005, p. 655). As already suggested, if one speaks from an acentric perspective, an utterance of the same sentence lacks the distinctive expressive dimension of its 'subjective' counterpart (but it may acquire other expressive characteristics). Speaking from an exocentric perspective, I intend to have my sentence assessed relative to contexts in which someone other than myself is specified and mutually known to be the judge (Lasersohn 2005, p. 670), but neither perspective requires the characteristic epistemic authority that comes with the egocentric perspective (idem, p. 655). Speaking on the basis of one's own experiences or affective experience and being authoritative about it will play a key role in explaining the function of the affective-expressive dimension of discourse that gives rise to the FD intuition.

FD is often taken to be evidence for assessment-relativism (Kölbel 2003, 2008, Lasersohn 2005). That 'most people have a healthy pre-theoretical intuition that there can be and are faultless disagreements' (Kölbel 2003, p. 54), is, notwithstanding the remarkable confidence expressed by the author, not evident. Generally speaking, if $\mathrm{X}$ asserts that $p$ and $\mathrm{Y}$ asserts that not- $p$, they disagree as to whether $p$, and at least one of them must be at fault. Huw Price takes the incoherence of faultless disagreement to be a key ingredient of an argument that aims at explaining why we have the truthpredicate in our language (and why, according to Price, minimalism about truth should therefore be rejected): if you assert that $p$ and I assert that $-p$ I come up with a criticism or condemnation of the original utterance (Price 2002). You have asserted what is (in my opinion) not true. You may well be justified in claiming that $p$, but justification does not amount to truth and it is the very essence of the norm of truth that it gives disagreement its immediate normative character:

'(T)he cautionary use of truth..., fixed by the rule

(R) It is a mistake to assert something not true

is a norm which speakers immediately assume to be breached by someone with whom they disagree, independently of any diagnosis of the source of the disagreement' (Price 2002, p. 167-8). ${ }^{12}$

Huw Price's truth norm (R) is stronger than the norm that what one says should represent what one believes or what one justifiably believes. Were these norms constitutive of assertion, disagreement would merely indicate that both speakers

\footnotetext{
12 The rule Price has in mind is best read in its negative formulation: If not-p, then it is incorrect to assert that $\mathrm{p}$; if not-p, there are prima facie grounds for censure of an assertion that $p$ (Price 2002, p. 10). Price (1983, p. 403), in a discussion of epistemic probabilities, holds that 'if two speakers endorse incompatible unqualified assertions, at least one of them is mistaken', and when there is a 'no fault'- disagreement, one must look at the force of the utterance to explain that intuition. Max Kölbel (2003) observes that FD (as defined by him) entails that Price's truth-principle must be rejected for particular types of discourse. A variant of the rule (If $p$ and one judges that not- $p$, then one is at fault), forms the basis of a simple formal proof that FD is impossible in Wright (2001) and Kölbel (2003, par. 2): Proof for reduction: assume that A judges that $p$ and B judges that not- $p$. Assume also that neither A nor B is at fault. Now, if $p$, then $\mathrm{B}$ is at fault, and if not- $p$, then $\mathrm{A}$ is at fault, which contradicts the second assumption.
} 
have different beliefs or have good grounds for their contradicting assertions (Price, idem.). ${ }^{13}$ Paul Boghossian voices scepticism about DF as follows: 'I am doubtful that we can ultimately make sense of the notion of a proposition that can sustain faultless disagreement. I don't see how any such proposition could serve as the plausible object of belief, the very thing for which the notion of a proposition is needed.' (Boghossian 2006, p. 36-37) ${ }^{14}$ Since neither Price nor Boghossian identify areas of discourse that could claim exception to (R), they suggest that $(\mathrm{R})$ governs our assertoric practice and that alleged exceptions should be explained away. ${ }^{15}$ Whether Price's truth norm for assertions is indeed the norm for assertions is doubtful, for reasons explored by Williamson (2000): other speech acts, like conjecturing that $p$, or correctly guessing that $p$, also fall under it. The latter is especially worrisome for cases like 'That's fun!' or 'This is tasty!', for in those cases I am not guessing or conjecturing that this or that is fun or tasty. On the contrary: I know, on the basis first person authority, that the designated object is fun (in some respect) or tasty, and put you in a position to know that, according to my standards (or judged from my perspective), it has that property.

Not all arguments against FD are equally convincing. As Crispin Wright (2006) points out, opposition to FD need not rest on an implausibly strong version of objectivism about matters of taste: what speakers bring into the open in paradigmatic FD discourses like Roller coaster or Tasting chili is how they evaluate things in the utterance situation and this is perfectly consistent with the possibility that one may later change one's mind, or that tastes can change, or that obtaining more information may modify the attitude. On the other hand, speaking about a past experience or attitude clearly affects the affective-expressive dimension. An important characteristic of the affective-expressive dimension of an utterance is that, as Cruse (1986) points out, it tells us something that is relevant in the utterance situation itself. In cases where one speaks about past experiences authority can be lost, which explains why it is harder to hear FD in

\section{(Past roller coaster)}

A: That roller coaster in Buenos Aires was fun.

B: No, it wasn't fun at all.

Here I may be mistaken in my assessment. But here is another phenomenon: Explicit past roller coaster does not exemplify, according to the standard definition of FD, and as acknowledged by MacFarlane and Kölbel, a genuine cases of FD:

\section{(Explicit roller coaster)}

A: I find that roller coaster fun.

B. I don't find it fun at all.

\footnotetext{
${ }^{13}$ But see again Kölbel (2003) for dissent.

${ }^{14}$ Compare Horwich 1990, p. 75, who states that a basic rule for the proper use of 'not' will include 'the principle that one never assert both ' $\mathrm{a}$ is $\mathrm{F}$ ' and ' $\mathrm{a}$ is not $\mathrm{F}$ '.

${ }^{15}$ Other semanticists who reject FD are Glanzberg (2007), Iacona (2008), Stanley (2005) and Stojanovic (2008). None of these authors explore the direction taken in this paper.
} 
This suggests that we can modify the affective-expressive dimension of an utterance by modifying semantic content, yet leaving the content asserted unaffected: the semantic content of I find that roller coaster fun is the same as the asserted content of uttering The roller coaster is fun (as used in Roller coaster) but only the latter utterance also carries an affective-expressive dimension. Call this the Problem of Lost Expressivity. ${ }^{16}$

A more serious problem for semantic solutions proposed by proponents of FD (and especially of the contextualist stripe) is that they owe us a demarcation of what counts as a predicates of taste, which is more easily said than done. Lasersohn holds that determining 'which predicates qualify as predicates of personal taste is an interesting question' (Lasersohn 2005, p. 644), but wisely postpones the discussion. If, as some proponents of semantic approaches acknowledge, FD is a phenomenon restricted to a certain class of predicates, it seems legitimate to ask which predicates give rise to it and providing a mere list of plausible candidates (prototypes: 'fun', 'spicy', 'disgusting', 'cool') is uninformative, since we're not being given a principle which unifies the list. Secondly, it seems that every predication, in an appropriate context and used in a right tone of voice could give rise to cases that intuitively fall under FD. Cappelen and Hawthorne (2009) suggest the example Now that's a knife!, uttered in a discussion among Australian macho's over what are 'really good knifes' (think of Crocodile Dundee). The following dialogue, spoken in the right tone of voice, has been proposed as a specimen of FD by Friederike Moltmann ${ }^{17}$ :

\section{(Sleeping on the sofa)}

A: One cannot sleep on this sofa!

B: One can sleep on this sofa.

In Sleeping on the sofa the interlocutors are correctly taken to give expression to opposing attitudes toward the salient sofa in the context of the conversation. The example illustrates an further feature of the expressive dimension of these utterances: a speaker need not describe her exact attitude with an appropriate predicate to express it and no description of her negative attitude towards the dormative properties of the salient sofa would exactly capture what she expresses- the relevant attitude may be simply ineffable. ${ }^{18}$ This is perfectly consistent with B's coming to know (on the basis of what she asserts) that, according to A, one can't

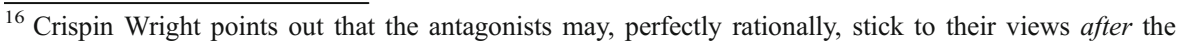
difference comes to light, a feature he calls the sustainability of one's contribution to the conversation (Wright 2006, p. 39). This is consistent with the possibility that his attitudes or experiences could change. Someone can stick to his guns and continue to claim that the roller coaster is fun for him and simultaneously realize that he (like many others before him) will eventually end up finding rides on roller coasters boring and uneventful. Response-dependence theories about taste (and related matters) reject proposals to objectify deliciousness or funniness and propose that what deserves those qualifications is determined by what well qualified judges find to be so. The problem with this proposal is that, as Wright (ibid., p. 39) points out, in simple disputes about relatively primary reactive attitudes we are simply not tempted to defer to experts. On the contrary: we consider ourselves to be perfectly well qualified as appropriate judges in basic matters of taste.

${ }^{17}$ During a discussion in Paris.

${ }^{18}$ In a slightly different (but related) discussion of the use of pejoratives, Potts (2006) calls this the ineffability of expressives.
} 
sleep on the sofa in question. A can and should be taken to have transmitted knowledge.

To make a plausible case for the communicative function of the affectiveexpressive dimension in discourse that seems to give to FD, we should remind ourselves that all cases under discussion involve active disagreement (in the sense specified in the introduction), a feature easily missed if one considers Kölbel's original definition:

'A faultless disagreement is a situation where there is a thinker A, a thinker B, and a proposition (content of judgment) $\mathrm{p}$ such that: A believes (judges) that $\mathrm{p}$ and $\mathrm{B}$ believes (judges) that not-p, and neither A nor B has made a mistake (is at fault) (Kölbel 2003, p. 54)

We may all have incompatible beliefs about what's delicious, spicy or fun, but we're not constantly involved in actively disagreeing about matters of taste, which is what happens in discourse that generates active disagreement. Secondly, by locating the problem at the level of thought, it is unclear why a semantic proposal would help solve the problem of FD. Thirdly, Kölbel's characterization a priori excludes that the expressive dimension of utterances could be relevant to the issue, since expressing an attitude explicitly pertains to acts that show, or reveal, one's attitudes (Green 2007). Fourth, when in the grip of a mood, feeling or attitude, we might also attempt to keep it inside (Green 2007, p. 23), but it would be strained to say that even those who hide their attitudes with great success could still be taken to disagree with each other. Lasersohn consistently discusses FD under the assumption that it involves active disagreement. Given the useful description of FD provided by Stojanovic (2008, § 2),

(i) For any two utterances $u$ and $u$ ' to a conversation $C$, the utterer of $u$ ' disagrees with the utterer $u$ only if: if $u$ is true, then $u^{\prime}$ is false, and if $u^{\prime}$ is false, then $u$ ' is true

(ii) The utterer of $u$ disagrees with the utterer of $u$ '

(iii) On the assumption that they are sincere, $u$ is a true utterance, and so is $u$ '.

the assessment-relativist who defends the existence of FD argues that lemma (i) must be revised (a contextualist solution doesn't acknowledge the FD-intuition and must therefore be rejected). MacFarlane (2007a) presents his key argument against contextualism as follows: 'The contextualist takes the subjectivity of a discourse to consist in the fact that it is covertly about the speaker (or perhaps a larger group picked out by the speaker's context and his intentions). Thus, in saying that apples are 'delicious', the speaker says, in effect, that apples are good to her (or to those in her group). In saying that a joke is 'funny', she says that it appropriately engages her sense of humour (or that of her group). (...) This kind of view has obvious appeal. It explains how the truth of the claims at issue can depend both on how things are with here explicit subject-matter (say, apples) and on how things are with a subject or subjects who is (sic) not explicitly mentioned. And it does so in a perfectly straightforward way, invoking semantic mechanisms that are already needed to handle more familiar kinds of context sensitivity exhibited by indexicals and demonstratives, quantifiers and gradable adjectives.' But, MacFarlane continues, '(T)he contextualist solution has a price. If in saying 'apples are delicious' I am 
saying that they taste good to me, while in saying 'apples are not delicious' you are denying that they taste good to you, then we are no(t) disagreeing with each other ... Intuitively, though, it does seem that we are disagreeing. We certainly take ourselves to be disagreeing. I may say: 'Wrong!' or 'That's false', neither of which would be appropriate if you had said explicitly that apples taste good to you' (MacFarlane 2007b, p. 18).

In his assessment of contextualist approaches to FD Lasersohn considers a technical variant of contextualism, by introducing in the proposition semantically expressed an unarticulated constituent. The sentence Roller coasters are fun expresses the proposition that roller coasters are fun according to my criteria for judging fun and The chilli is tasty expresses the proposition that the chilli is tasty according to my criteria for judging tastiness. But, Lasersohn continues, 'This solution can't be right, however... because of the relation between content and contradiction.... If I say 'Roller coasters are fun', and you say, 'No, roller coasters are not fun', on this analysis, you are not contradicting me, because the negated sentence doesn't express the same content for you as it does for me. In effect, my utterance means roller coasters are fun for me, and your utterance means roller coasters aren't fun for you, and there is no conflict between those at all-indeed, there is no reason to think we disagree in any way, on this analysis' (Lasersohn 2005, p. 649). Since Kölbel, MacFarlane and Lasersohn assume that FD exists, a contextualist strategy for analyzing utterances in FD discourse must be rejected. ${ }^{19}$

However, this prima facie plausible move of the assessment-relativist overlooks a feature of FD-discourse that non-FD dialogues arguably don't exemplify: in making reference to standards or judges explicit at more articulated level of semantic content and taking the speaker to have asserted something that is equivalent to that content, the affective-expressive dimension of the utterance changes or even goes missing, something which is not acknowledged by the anti-contextualist argument, which only registers loss of disagreement.

Consider the following question: why would a perfectly analogue proposal with assessment-relativism about taste, but now applied to a subject matter that doesn't involve taste, be unmotivated? Consider the predicate 'is expensive':

\section{(Expensive Porsches)}

A: Porsches are expensive.

B: No, they're not. They are cheap.

Once it is clear that there can be different monetary parameters, it will become clear whether A or B has made either a cognitive mistake or have been relying on different standards. Why couldn't this give rise to the following form of monetary relativism?

\section{(Monetary relativism)}

' $a$ is expensive' is true relative to $<\mathrm{w}, \mathrm{t}, \mathrm{m}>$ iff for some contexts $\mathrm{c}_{1}, \mathrm{c}_{2}, \mathrm{c}_{3}$, ' $a$

\footnotetext{
${ }^{19}$ See also Crispin Wright (2006, p. 39-40) for a brief discussion. Soames 2003, p. 303 ff. nicely documents that G.E. Moore and C.L. Stevenson used the same argument against forms of egoism in ethics, roughly the view that ethical statements are psychological claims about what one prefers.
} 
is expensive' is true as used in $c_{1}$ and assessed from $c_{2}$, but not true as used in $\mathrm{c}_{1}$ and assessed from $\mathrm{c}_{3}$ (keeping $\mathrm{w}$ and $\mathrm{t}$ constant).

Although technically impeccable, the proposal is unmotivated: Expensive Porsches doesn't generate an FD intuition and, as we have seen, it was the FD intuition that fuels the various semantic proposals underlying assessment relativism. But the move from an FD intuition to a semantic solution overlooks a further feature that distinguishes Expensive Porsches from Sexy Porsches:

\section{(Sexy Porsches)}

A: Porsches are sexy!

B: No, they're exhibition pieces for the rich!

In Sexy Porsches the role of the subject is not confined to its role as judge or provider of standards (standards for sexiness, standards for expensiveness); his attitudes or experiences are also relevant as qua attitudes expressed. Assessment relativism oversees an aspect of Sexy Porsches, Roller coaster and Chili tasting not present in Expensive Porsches: the presence c.q. absence of the FD intuition correlates with the presence or absence of an expressive dimension carried by the utterances. The example suggests further evidence for a link between the emergence of an FD intuition and the affective-expressive dimension of utterances. I will first discuss the assertive dimension and then the affective-expressive dimension.

\section{The Assertive Dimension}

None of the parties in the debate over FD can reasonably deny that contributions to FD-dialogues can be correct assertions. Even when B in Roller coaster would have said 'No, it's not', he would have used a sentence uttered by A to assert that roller coasters are not fun for him (B). (see footnote 21 for the function of 'No' in such replies.) One way to appreciate the original contextualist intuition that the level of content it identifies is indispensable is that what was left unarticulated in the semantic content of the sentence can be made part of the proposition asserted by the speaker. And making it part of the asserted content is necessary because, qua assertors, contributions to FD discourse transmit knowledge, and can be taken to obey constitutive rules for correct assertions. A now popular proposal for the constitutive rule of assertion, stronger than the one discussed earlier (Huw Price's proposal), was proposed by Williamson (2000):

\section{(Rule of Assertion)}

One must ((assert $p)$ only if one knows that $p$ )

The Rule of Assertion, which partly individuates the speech act of assertion (Williamson 2000) also constrains what can be taken as the content of the speaker's assertion - a content which is, as contextualists and speech act pluralists can agree on, an enriched and/or modified version of the utterance's compositionally determined semantic content. Consider A's contribution to Roller coaster: its 
asserted content is what the audience comes into a position to know, namely that, according to the speaker, the roller coaster is fun. ${ }^{20}$ That is what the intended audience comes to know, and what the speaker can be taken to have asserted. This is well captured by an observation of Garcia-Carpintero (2004, p. 156), who extends Williamson's original rule as follows:

\section{(Modified Rule of Assertion)}

One must ((assert $p$ ) only if one's audience comes thereby to be in a position to know $p$ )

The speaker's intended or preferred audience does not come to know that roller coasters are fun for the audience may in fact hate roller coasters. If the contributors act according to the Rule (or Modified Rule) of Assertion - and there is nothing that prevents them from doing so - there is no disagreement for they assert (and are taken to have asserted) different propositions. ${ }^{21}$ Note that the speaker cannot be taken to have asserted that roller coasters are fun (period), for it could not be true that just by asserting that, his audience comes in a position to know that roller coasters are fun. The speaker's intended audience may in fact hate roller coasters (and this fact may be common knowledge), and so what she comes to know must be weaker than the proposed asserted content (see Borg 2004 for arguments to the effect that the sentence Roller coasters are fun has syntactically determined truth conditions). Our approach thus supports Soames (2002) in that speaker-intentions are relevant to get at what's asserted.

However, taking into account only the appropriate asserted content as what is communicated would resuot in an impoverished picture of what the speaker's overall speech act communicates (in a broad sense of that word). This brings us back to the problem of the Lost Expressivity (cf. supra). If one takes the asserted content of A in Roller coaster to be that roller coasters are fun for him, and assumes that content to be explicitly uttered, as in

\section{(Explicit roller coaster)}

A: The roller coaster is fun according to my standards

B: It's not fun according to my standards.

the expressive dimension in contributions is seriously modified if not fully absent. Since in Explicit roller coaster A and B's respective utterances have a semantic content which is the same as the asserted contents in Roller coaster, some third factor must be responsible for generating the FD intuition that comes with Roller coaster but not with Explicit roller roaster. When speakers make explicit reference to themselves qua judges or qua owners of standards, we experience loss of

\footnotetext{
${ }^{20}$ Contrary to Cappelen and Lepore's quite liberal conception of 'what is said', I see Williamson's rule of assertion as offering a constraint on what the speaker can be taken to have asserted: what he asserted must be assumed to be known by him and specify what the audience thereby comes into a position to know. Adherence to the Rule of Assertion may require that the semantic content of the utterance be appropriately enriched with unarticulated material at the level of semantic content. A further constraint on asserted contents, assumed but not discussed in this paper, is that asserted content must be intended to assert by the speaker. Cappelen $(2007,2010)$ denies this and rejects on these grounds Williamson's norm of assertion. I disagree with this move but will not explore that line in this paper.

${ }^{21}$ There must be norms for the correct uptake, or interpretation, by the intended audience, of an assertion and it remains to be shown how they relate to the speaker-oriented norm Williamson proposes.
} 
expressivity and the sense that their contributions generate an attitudinal conflict disappears. This phenomenon predicts that if it is common knowledge among those involved that the egocentric perspective is absent, the expressive dimension, insofar as it pertains to the attitude expressed in the original egocentric examples, will be absent and no FD intuitions can arise. Consider an exocentric case, i.e. a conversation about young Billy, who is enjoying a ride on the roller coaster:

\section{(Young Billy on the roller coaster)}

A: The roller coaster is fun.

B: No, it's not fun at all.

(compare Lasersohn 2005, p. 672). Since it is mutual knowledge that A and B are talking about Billy's experiences, the contributions fuel neither the FD intuition nor assessment relativism. Technically, the assessment-relativist approach can be extended to these cases (as Lasersohn and MacFarlane convincingly show), but the original motivation for the proposal rested on cases in which an FD-intuition arises, and these were uniformly cases in which the affective-expressive dimension was relevant: at a minimum, both speakers were expressing, not describing their attitudes (that is why the classic Stevenson-Ayer expressivism struck a chord with so many). Note, moreover, that in Young Billy on the roller coaster there is a factual disagreement: A asserts, while B denies, that Billy is having fun on the roller coaster.

MacFarlane (2007a, p. 29-30) imagines a world in which people never utter 'Apples are delicious' but only utter 'Apples are very pleasing to my taste buds', or never utter 'That joke was funny', but only 'That joke was amusing to me'. In such a world there would be less controversy (according to MacFarlane). This suggests that only by uttering the former sentence I hope to change your attitudes, but the observation also shows that leaving the standard of the speaker or a reference to the speaker unarticulated at the level of semantic content has a communicative function: not articulating it is not due to articulatory laziness or communicative bottlenecks (Levinson 2000, who uses this explanation to account for generalized Gricean implicatures). It has a distinctive communicative function, for it highlights the affective-expressive dimension that characterize discourse that leads to disputes over matters of taste. Semantic approaches that take

\section{(1) The roller coaster is fun}

to be semantically equivalent with (i.e. having the same truth conditions as)

(2) The roller coaster is fun according to my standards

leave out a crucial explanandum: why speakers may have a preference for uttering sentence (1) rather than (2). Note that assessment relativism must accept that (2) provides an asserted content of an utterance of (1) which carries an affectiveexpressive dimension, for every parameter that functions in an index against which a proposition is evaluated can always be integrated in a richer proposition such that $i t$ is evaluable against a world simpliciter (as in Kaplan 1977/1989). Any version of assessment-relativism which adds a standard of taste parameter to the circumstances of evaluation must acknowledge that we have to identify an asserted content which includes those standards when we come to know what was asserted by the speaker. (In this sense, there is coordination of contexts going on at the level of asserted 
contents.) This suffices to show that there must a further non-semantic communicative reason for preferring uttering (1) over (2), although they may both serve to assert the same proposition. The case once again illustrates that the attitudinal conflict is not located at the level of asserted content; the dispute involves the affective-expressive dimensions of the speech acts both speakers contribute to a discourse.

A final argument for the claim that proponents of FD overlook the expressive dimension in their explanatory framework involves cases which cannot (on their account) qualify as exemplifying FD, even though they have all the look and feel of standard FD cases. Consider a dispute over what to order in the gelateria:

\section{(Banana or strawberry)}

A: This ${ }_{i}$ is delicious!

B: No, That ${ }_{j}$ 's delicious!

Since A and B semantically express different propositions (they are pointing to different types of ice-cream), Banana or strawberry can't be a case of FD, yet an attitudinal conflict seems to have been generated: in the context of the conversation, A and B express different preferences. The example also illustrates that the function of 'No' need not be confined to that of negating a proposition. B's 'No' is better described as the disassociating use of negation: B disassociates herself from a proposition $p$, and offers a proposition $q$ (which is technically consistent with $p$ )

We arrive at two preliminary conclusions: (i) the FD intuition does arise in contexts that do not give rise to what assessment relativists take to be genuine cases of FD, and (ii) a correct identification of the asserted content asserted in FD exchanges must allow for knowledge to be transmitted (there is no disagreement on the level of asserted content). Yet, this does not preclude the emergence of an attitudinal conflict: a further dimension, the affective-expressive dimension-must be in play. This would explain the FD intuition: the faultless-component derives from the fact that speakers are authoritative about what they express when expressing it; and yet, there is no genuine disagreement at the level of asserted content for there is not one proposition that is asserted by one party and denied by the other. Still, the exchange reveals an attitudinal conflict that must somehow be resolved. So what is it about expressing attitudes (over and above asserting that one has that attitude) that it generates this sense of conflict?

\section{The Affective-Expressive Dimension}

As Bar-on and Long (2001), Von Fintel \& Gillies (2007) and Boisvert (2008) point out, there are no a priori reasons to think that utterances, just because they have a compositionally determined semantic content (they are not like 'cool!' or 'yuck!' or a frown) and are produced in order to assert more complex propositions, cannot also enjoy an affective-expressive dimension. If A utters 'The roller coaster is fun' (as in Roller coaster), he asserts that according to his standards, the roller coaster is fun. The affective-expressive dimension of this utterance (when said in the right tone and voice, and absent when the asserted content amounts to an empirical propositions) 
publicizes an attitude the presence of which the speaker cannot be mistaken about at the time of producing the utterance, hence the intuition of faultlessness. ${ }^{22}$ The speaker is giving voice to the attitude. Unlike Finkelstein (2008), however, I would not give the act of expressing itself an assertoric dimension. The fact (true proposition) of having expressed an experience or sentiment $E$ has propositional character (for it is evidence - in fact: excellent evidence-that the speaker has that attitude), ${ }^{23}$ but expressing $E$ is different from asserting that one has $E$ (or is in $E$ ).

What is the function of expressing an attitude, as distinguished from representing oneself as knowing $p$ (where $p$ articulates that one has that attitude)? And what is required from the audience to appreciate the affective-expressive dimension of an utterance if it has one? The affective-expressive dimension of speech acts follows a general pattern of self-expression as captured by Green (2007):

\section{(Self-Expression)}

Where $\mathrm{A}$ is an agent and $\mathrm{B}$ a cognitive, affective or experiential state of a sort to which A can have introspective access, A expresses her B if and only if A is in state B, and some action or behaviour of A's shows and signals her B (Green 2007, p. 43)

The primary result of expressing is that an attitude is shown and its initial effect is to display commitment in that it severely narrows down the speaker's options viz à viz the intended audience. As Green puts it, the speaker 'sticks out his neck and so creates a liability to error or exposed insincerity: if the speaker is not in the mental condition expressed, she is subject to a severe loss of credibility' (Green 2008, p. 275). ${ }^{24}$ Expressing an attitude (experience, sentiment) $E$ thus sharply differs from conversationally implicating that one has attitude $E$ for implicatures characteristically allow for 'plausible denial' (what is conversationally implicated by a speaker can be cancelled, as Grice pointed out), while expressing $E$ accentuates commitment. Canceling the affective-expressive dimension is out of the question if not downward incoherent behavior.

Turning to the intended audience, making sense of the speaker's act of expressing an attitude appeals to specific capacity of the audience in that she is invited to empathize with the expresser, and that might well be the best way to realize the ultimate aim of expressing: activating in the speaker's intended or preferred audience, via mental simulation, a 'faint image' of $E$ is an excellent means to get the intended audience into appreciating, and perhaps adopting the same attitude towards the object or state of affairs in question. To achieve that goal, two conditions must be satisfied. First, the imagined reaction in the intended audience must be more

\footnotetext{
${ }^{22}$ Note that, since the affective-expressive dimension reveals something about the speaker, its correct interpretation constitutes evidence about the speaker's having that attitude (see Williamson 2000 for an extensive defense of the propositional character of evidence). That $\mathrm{x}$ has expressed attitude $E$ - the expression of $E$-is evidence, hence propositional; but that proposition (the proposition that X expressed E) was itself not expressed.

${ }^{23}$ The 'multiple speech act option' for evidentials and epistemic modals is briefly explored but not developed in von Fintel and Gillies (2007). I see this option as no more problematic than the fact that one can say something and thereby implicate various other propositions. In terms of commitment/absence of commitment, implicating something seems to be the perfect communicative counterpart of expressing something in the sense explored in this paper.

${ }^{24}$ Green refers to Grafen's (1991) work in evolutionary psychology on handicaps.
} 
or less accurate. As Green (2007, p. 187) puts it, 'it must track down how things are with (me) if it is to count as empathizing'. Secondly, it is not sufficient to ascribe attitude $E$ to me (that is what happens when I understand the assertive dimension of the utterance: one purpose of presenting myself to you, in an assertion, as believing that I have $E$ is that you indeed come to know that I have $E$ ). You must also imagine yourself having the relevant attitude. Empathizing requires that the imagined attitude is a correct image of the one expressed, and that it is imagined de se. From the perspective of the expresser: once I have thus put you in my shoes, '(you are) likely to come to (my) aid, join forces with me, become my ally' (Green 2007, p. 187, slightly adapted). Although the speaker need not intend that the audience will eventually adopt a similar attitude towards the salient object (by taking it out of the imagination box and putting it into the belief-box, so to use some jargon borrowed from Jerry Fodor), there is, as Kant pointed out, a recommending dimension to the judgment of taste, a proposal to adopt the same viewpoint, and not just to imagine my point of view. ${ }^{25}$

Empathy explains how to make sense of the distinctively subject-transcendent dimension of the affective-expressive dimension of a judgment of taste, a dimension neglected in contextualist and assessment-relativist approaches. For example, when A utters One can't sleep in this sofa he is, by expressing his negative attitude, steering the intended audience's mind in the direction of appreciating that (negative) attitude towards the object he refers to (and perhaps conversationally implicates that the audience provide a real bed for him). You, the intended audience, are invited to simulate an attitude for yourself (the de se element), which might be a first step toward actually adopting my attitude. 'Invited' and 'an attitude' is important, because expressing $E$ can also activate in the intended audience a quite different, perhaps opposite attitude. Then, an attitudinal conflict between both contributors is brought into the open. ${ }^{26}$

The subject-transcendent character of the expressive dimension of judgments that seem to give rise to FD was, as already hinted at, recognized by Immanuel Kant. In an important new categorization of speech acts, Rebecca Kukla and Mark Lance (2009) propose to classify speech acts according to agent-involvement or agentneutrality of their input (which are attitudes of the speaker, in this context) and output (the agents whose attitudes should be affected) in conversational interactions. For our purposes it suffices to notice that the expressive dimension of an utterance $u$ involves, in Kukla and Lance's terminology, agent-relative input and agent-neutral output. The agent-relative input is constituted by a personal encounter with the object of judgment, and the judgments are singular in the sense that they are about that object and not inferred from a general statement or principle from which the singular judgment is supposed to follow (this, of course, is one way of account for the 'faultless' dimension). The agent-neutral output is a judgment in which 'one speaks with a universal voice', and Kukla and Lance refer to Kant's analysis of judgments of taste as a prime example of such a judgment. ${ }^{27}$ According to Kant, the communicative situation in which judgments of taste (as they figure in FD-

\footnotetext{
${ }^{25}$ See Kemal (1986, p. 178) for a persuasive interpretation of Kant along these lines.

${ }^{26}$ I owe this observation to J. Maria Rodrigues.

27 Another example are what they call 'observatives', like 'Lo, a rabbit', which differs from such reports as I see a rabbit, which differ in pragmatic structure insofar as the former, but not the latter, has an agent relative input.
} 
discourse) are embedded is that of an agent who (i) experiences an object or situation in some way or other, which (ii) causes pleasure that is (iii) the evidential ground for $\mathrm{S}$ ' judgment that the object is, say, beautiful. Moreover, Kant held that, 'although my judgment of taste requires a personal encounter, in so judging I impute this judgment agent-neutrality... In judging I demand universal agreement' (Kant, as cited in Kukla and Lance 2009, p. 44).

We now understand (and describe in jargon obviously not available to him) where Kant's demand comes from, and, more intriguingly, how it connects with the phenomenon of Lost Expressivity. Expressing an attitude appeals to the audience's imaginative powers. When I utter I find the roller coaster fun, you come to know something about me (just as you could come to know that fact about me by communicating with my friend, say). Expressing my attitude towards the roller coaster, I speak, as Kant suggests, with a universal voice. Not literally or explicitly, of course: I achieve 'enough universality' by getting you to imagine yourself having a similar attitude or experience towards the roller coaster, something I cannot achieve by pointing out or asserting that I myself find the roller coaster fun. Uttering a sentence with that semantic content would make it impossible to exploit the subject-transcendent element involved in the affective-expressive dimension. Explicit reference to oneself or one's own experience in the semantic content of the utterance does not invite the intended audience to empathize with me. Compare (1) and (2):

(1) This is fun! (?but I'm not trying to get you on the roller coaster)

(2) I find this fun, but you won't find this fun.

The oddness of (1) is due to the fact that the affective-expressive dimension aims at getting the audience to mentally simulate being in same state for herself, inviting her to form a faint copy of the same response the speaker had, which is a process not activated by more explicit statements like (2). The underlying affective difference between 'this is fun' and 'I find this fun' can be described with what Kant might have had in mind: the truth of the semantic content of (1) (without the comment) anticipates a perfect world in which everyone, or at least my preferred audience, comes share my attitude, i.e. a world in which disagreement (with me, about that issue) is absent.

The 'universal voice' associated with the affective-expressive dimension of a judgment of taste is not adequately captured by adding in the asserted content a reference to a community. François Recanati (2008, p. 59) thus errs when he says that "when the speaker says 'It's beautiful', she means something intuitively stronger than merely 'it is beautiful to my standards or 'If find it beautiful'. (...) this gives us a hint as to what the proper analysis of the stronger, unqualified statement should be. I suggest the following: 'It is beautiful' means something like It is beautiful for us, that is, for the community to which speaker and hearer belong. When the audience says, 'No it isn't', the speaker realizes that the stronger statement is incorrect (since the audience does not actually find the painting beautiful), and she retreats to a weaker statement" (Recanati 2008, p. 59). This can't be true. If the speaker had in mind what Recanati suggests, she would have made a straightforward empirical statement and the faultless character of her contribution would be lost. Secondly, the asserted content proposed by Recanati does not fit what the intended audience does 
come to know (that the speaker finds the painting beautiful, not that it is beautiful for $u s$ ). The universal dimension is thus not an ingredient of the asserted content, but an aspect of the affective-expressive force of the statement, and one that would be lost if the asserted content would have been fully articulated in the utterance. The pragmatic structure of the affective-expressive dimension is, as Kukla \& Lance (2009, p. 42, 43) put it, 'structurally indexed to an agent ... with a particular normative position that is not generalizable even in the ideal... (yet) it must pass on entitlements and commitments that are not indexed to particular agents, but are rather public. (...) in judging I demand universal agreement...'. Recanati correctly identifies a stronger element, but mislocates its relevance by assigning it a place at the level of what's asserted.

When you and I express different attitudes about a salient subject matter, a latent conflict emerges: you are, with others, invited to form an attitude, and the one you happen to form in fact conflicts with mine. There is, when opposing attitudes are expressed in a conversation, not just a public conflict an outsider can take notice of, but also, and perhaps even more subtly, my experience of a conflict with you (and vice versa), for your reaction is the formation of an attitude which conflicts with the one I actually happen to enjoy, and I am invited to form that attitude myself. That explains why a conflict generated by expressing opposing attitudes results in more than just the cognitive registration of a difference of opinion about which we can 'agree to disagree'. When you and I express opposite attitudes we generate an attitudinal conflict, for we incur different commitments. And such a conflict cannot be solved by mere coordination of standards or contexts (MacFarlane 2007a, p. 30). Coordination of contexts is required to solve semantic problems and has an important function in identifying appropriate asserted contents, but it cannot resolve deep attitudinal conflicts about what's tasty or fun or sexy. ${ }^{28}$

Open Access This article is distributed under the terms of the Creative Commons Attribution Noncommercial License which permits any noncommercial use, distribution, and reproduction in any medium, provided the original author(s) and source are credited.

\section{References}

Ayer, A. J. (1948). Language, truth and logic (2nd ed.). London: Victor Gollancz.

Bar-on, D., \& Long, D. C. (2001). Avowals and first person privilege. Philosophy and Phenomenological Research, 62, 311-335.

Boghossian, P. (2006). What is relativism? In P. Greenhough \& M. P. Lynch (Eds.), Truth and realism (pp. 13-37). Oxford: UP.

Boisvert, D. (2008). Expressive-assertivism. Pacific Philosophical Quarterly, 89, 169-203.

Borg, E. (2004). Minimal semantics. Oxford: UP.

Buekens, F. (2009). Faultless Disagreement and Self-Expression. In J. M. Larrazabal and L. Zubeldia (Eds.), Meaning, Content and Argument. Proceedings of the ILCCI International Workshop on Semantics, Pragmatics and Rhetoric (pp. 249-267). San Sebastian: Esukal Herrikeko Press.

\footnotetext{
${ }^{28}$ I would like to thank Pascal Engel and Adam Carter for comments at a workshop in Geneva, where this paper was read. An earlier version was read at a workshop on Expression and the Inner in Oviedo, where Barry Stroud and Luis Valdez-Vallanueva gave valuable comments.
} 
Cappelen, H., \& Hawthorne, J. (2009). Relativism and monadic truth. Oxford: UP.

Cappelen, H., \& LePore, E. (2004). Insensitive semantics. Oxford: Blackwell.

Cruse, D. A. (1986). Lexical semantics. Cambridge: Cambridge University Press.

Finkelstein, D. (2008). Expression and the inner. Cambridge: Harvard University Press.

Garcia-Carpintero, M. (2004). Assertion and the semantics of force-markers. In C. Bianchi (Ed.), The semantic/pragmatics distinction. Stanford: CSLI.

Geach, P. (1965). Assertion. Philosophical Review, 74, 449-465.

Glanzberg, M. (2007). Context, content, and relativism. Philosophical Studies, 136, 1-29.

Green, M. (2007). Self expression. Oxford: UP.

Green, M. (2008). How do speech acts express psychological states? In S. Tsohatzidis (Ed.), John Searle's philosophy of language: Force, meaning and mind. Cambridge: Cambridge University Press.

Horwich, P. (1990). Truth. Oxford: Blackwell.

Kaplan, D. (1989). Demonstratives. In J. Perry, J. Almog, et al. (Eds.), Themes from Kaplan. Oxford: Clarendon.

Kemal, S. (1986). Kant and fine art. An essay on Kant and the philosophy of fine art and culture. Oxford: Clarendon.

Kölbel, M. (2002). Truth without objectivity. London: Routledge.

Kölbel, M. (2003). Faultless disagreement. Proceedings of the Aristotelian Society, 104, 53-73.

Kölbel, M. (2008). Introduction: Motivations for Relativism. In M. Garcia-Carpintero and M. Kölbel (Eds.), Relative Truth (pp. 1-38). Oxford: UP.

Kölbel, M. (2009). 'The evidence for relativism', in Synthese 2009: 375-395.

Kukla, R., \& Lance, M. (2009). 'Yo!' and 'lo!'. The pragmatic topography of the space of reasons. Harvard: University Press.

Lasersohn, P. (2005). Context-dependence, disagreement, and predicates of personal taste. Linguistics and Philosophy, 28, 643-686.

Levinson, S. (2000). Presumptive meaning. The Theory of generalized conversational implicature. Cambridge: MIT.

MacFarlane, J. (2007a). Relativism and disagreement. Philosophical Studies, 132, 17-31.

MacFarlane, J. (2007b). 'Truth and subjectivity' (unpublished).

Moltmann, F. (2009). 'Relative truth and the first person', in Philosophical Studies 134 (online first).

Perry, J. (1986/1998). 'Thought without representation'. In J. Perry (Ed.), The problem of the essential indexical and other essays. New York: Oxford University Press.

Potts, C. (2006). The expressive dimension. Theoretical Linguistics, 32(2), 165-197.

Price, H. (1983). Does 'probably' modify sense? Australasian Journal of Philosophy, 61, 396-408.

Price, H. (1988). 'Two paths to pragmatism II'; in R. Casati and C. Tappolet (eds.). European Review of Philosophy, 3, 109-147.

Price, H. (2002). Truth as convenient friction. Journal of Philosophy, 100, 167-190.

Recanati, F. (2008). 'Moderate relativism'. In M. García-Carpintero and M. Kölbel (Eds.), Relative truth. Oxford University Press.

Schroeder, M. (2008). Being For. Evaluating the semantic program of expressivism. Oxford: UP.

Soames, S. (2002). Beyond rigidity: The unfinished agenda of naming and necessity. Oxford: UP.

Soames, S. (2003). Philosophical analysis in the twentieth century. Volume 1: The dawn of analysis. Princeton: Princeton University Press.

Soames, S. (2007). Philosophical essays volume I. Natural language: What it means and how we use it. Princeton: Princeton University Press.

Stanley, J. (2005). Knowledge and practical interests. Oxford: Clarendon.

Stojanovic, I. (2008). 'Talking about taste: Disagreement, implicit arguments, and relative truth'. Linguistics \& Philosophy.

Von Fintel, K., \& Gillies, A. (2007). 'An opinionated guide to epistemic modality', in Oxford Studies in Epistemology (pp. 32-63). Oxford: UP.

Williamson, T. (2000). Knowledge and its Limits. Oxford: Oxford University Press.

Wright, L. (1973). Functions. Philosophical Review, 82(2), 139-168.

Wright, C. (2006). Intuitionism, realism, relativism, and rhubarb. In P. Greenhough \& M. P. Lynch (Eds.), Truth and realism (pp. 38-60). Oxford: UP. 